\title{
Rock Mass Characteristics and Tomographic Data
}

\author{
J. Vatcher ${ }^{1}$ (1) S. D. McKinnon ${ }^{2} \cdot J_{\text {J. Sjöberg }}{ }^{1}$ \\ Received: 3 October 2017 / Accepted: 30 January 2018 / Published online: 5 March 2018 \\ (c) The Author(s) 2018. This article is an open access publication
}

Keywords Geomechanical environment $\cdot$ Velocity tomography $\cdot$ Velocity structure $\cdot$ Rock mass properties

\section{Introduction}

Good quality geomechanics data are as hard to come by in mining engineering as it is to find a geomechanics report that does not recommend more data collection. There is wide acceptance of the fact that data are integral to our understanding of the rock mass. An even higher value is placed on data that can be obtained and used in advance of drifting.

Unfortunately, our current methods of data acquisition limit quality and usefulness. The most commonly available data before drifting consist of drill core mapping. Boreholes are often few and far between due to their costs, with their spacing often too wide for accurate interpolation of geomechanical characteristics. Additionally, core mapping involves significant resources, and it is not necessarily clear what information is useful. After drifting, mapping of limited faces is possible, but building a 3-D model of these data can be difficult due to poor spatial coverage.

Additional data acquisition techniques are needed. Those who work in rock mechanics dream about methods that are non-invasive, inexpensive, robust, and reliable. Approaches that can provide information about the geomechanical characteristics of the rock mass as soon as possible enable timely, risk-mitigating design.

It is with this in mind that correlations between velocity tomography and geomechanical characteristics are explored. Tomographic velocity models are based on seismic wave travel times within a seismic monitoring sensor array. These

J. Vatcher: Formerly Luleå University of Technology, Luleå, Sweden.

J. Vatcher

jessa@itasca.se

1 Itasca Consultants AB, Aurorum 2, 97775 Luleå, Sweden

2 Robert M. Buchan Department of Mining, Queen's University, Goodwin Hall, 25 Union St, Kingston, ON K7L 3N6, Canada techniques have been used extensively and successfully in the Earth Sciences to map characteristics of the Earth at great depths, for example, the identification of the Mohorovicic Discontinuity (Moho); see Rawlinson et al. (2010) for a description of the history of tomographic techniques. To a lesser extent, these techniques have been applied in the mining environment, which is at a much smaller scale, where correlations between velocities and i) geomechanical characteristics of the rock mass (Cai et al. 2014; Hemmati Nourani et al. 2017; Watanabe and Sassa 1996), and ii) stress anomalies (Cao et al. 2015; Friedel et al. 1995, 1997; He et al. 2011; Hosseini et al. 2013; Krauß et al. 2014; Luxbacher et al. 2008; Ma et al. 2016; Young and Maxwell 1992) are evaluated. Much of this work was conducted in soft rock environments (coal mines). A general consensus about the usefulness of tomography in hard rock environments is not yet exhibited in the literature.

The intention of this technical note is to present the evaluation of possible correlations between the velocity models created by Lund et al. (2017) and the geomechanical model created by Vatcher et al. (2016) for the Luossavaara-Kiirunavaara AB (LKAB) Kiirunavaara Mine, Sweden. If such correlations exist, tomography is a relatively inexpensive exploration method that may provide insight into the characteristics of the rock mass.

A brief background on the two input data sources is given, followed by the grid-based statistical analysis required to understand the data and their potential correlation. Results are discussed with focus on the potential and limitations of tomographic data for rock mass characterization at the Kiirunavaara Mine. Concluding remarks are offered, which expand the results to a broader range of geological settings. 


\section{Background and Methodology}

The Kiirunavaara Mine uses sublevel caving to produce approximately 28 million tonnes of iron ore per annum. It has been seismically active since 2008 due to the depth and volume of excavation. More information about the onset of seismicity is described by Dahnér et al. (2012).

A three-dimensional (3-D) geomechanical model was developed by Vatcher et al. (2016) based on statistical and spatial analysis of available data. This model showed that the geomechanical setting of the Kiirunavaara Mine is markedly different compared to a typical hard rock underground mine. In particular, there is a significant clay alteration in the volume analysed, in the form of large contiguous volumes, lenses, and joint filling. The clay model has been calibrated over a specific volume in the mine (in mine coordinates, approximately Y28 through Y44 [1600 m long] from Level $1022 \mathrm{~m}$ to Level $1165 \mathrm{~m}$ (140 m deep)). The block model of rock quality designation (RQD) created by Vatcher et al. (2016) using inverse distance showed a halo of reduced values in the intact rock surrounding the clay volumes. The resolution of this model is $60 \mathrm{~m}$, and it spans almost the entire mine.

Lund et al. (2017) created passive tomography models using the available seismic data at the mine. Models of Pand $\mathrm{S}$-wave velocities were created for the individual years 2013, 2014, and 2015. The models are in the form of gridded data points where the cell size is $10 \times 10 \times 10 \mathrm{~m}$ in the cardinal directions of the mine. A large portion of these models have a maximum resolution of $60 \mathrm{~m}$, i.e. features with dimensions less than this are poorly resolved. Data points that had a coarser resolution were not used in this analysis. The model spans over a specific volume in the mine [in mine coordinates, approximately Y25-Y43 (1800 m long), between $\mathrm{x}$-coordinates of $5800 \mathrm{~m}-6800 \mathrm{~m}$ (1000 m wide) and z-coordinates of 675-1445 m (770 m deep)], which is partially covered by the clay and RQD models.

The analysis presented in this technical note relies on the assumption that the stress changes in the volume covered by the tomographic model result in negligible changes to the velocities. Based on previous numerical modelling results, for example Vatcher et al. $(2014,2017)$, this is considered to be an appropriate assumption for the time periods studied. Due to the size of the mine, production progresses slowly in a vertical direction. Only two new levels were opened between 2013 and 2015 in this volume. In addition, the number of tomographic data points located in volumes that should experience stress changes due to production is few compared to the remaining data points. Velocity changes between the three tomographic models caused by stress changes are thus not expected. Only data points that have data for all years were included in this analysis.
Due to this assumption, for purposes of this analysis velocity changes for each data point between the three annual models are considered to represent the inherent error (1) in the underlying data and (2) caused by the tomographic model building process, which are commonly referred to as artefacts. Passive tomography relies upon repetition of wave paths. However, since it is passive, there is no control over the source location or which sensors are used to identify the events. Wave travelpaths may significantly alter between the years. This has the potential to result in differences in the tomographic models, which for purposes of this analysis represent the precision of the tomographic models. Since this analysis is comparative, accuracy is of less concern.

This analysis begins by evaluating how the tomographic models change between 2013 and 2015. Through an understanding of model error, one gains perspective on the statistical significance of velocity changes. The individual tomographic models are then compared to the two viable components of the geomechanical model: (1) RQD and (2) the clay volumes. Analysis was completed for both P- and $\mathrm{S}$-wave velocities.

\section{Results}

\subsection{Tomographic Model Precision and Error Statistics}

The distributions of the differences between each data point for every year for both the P- and S-wave velocities were approximately centred around $0 \mathrm{~m} / \mathrm{s}$ (Fig. 1), meaning that the majority of data points in the model change very little throughout time (high precision). A statistical description of these distributions is presented in Table 1. These distributions represent errors associated with the data and the tomographic modelling, thereby giving a basis to identify if correlations between the velocity models and the geomechanical model are significant. No spatial patterns in the differences data were identified via visual analysis.

\subsection{RQD}

The velocity models did not show any correlation with the RQD model. An example of this is shown in Fig. 2, with the P-wave velocities in the 2014 tomographic model compared to the nearest RQD data point. The passive tomography results do not signify changes in the upscaled measure of core fracture (RQD block model).

\subsection{Clay}

Identification of clay volumes via tomographic data, however, shows more promise. The average velocities inside and 
outside of the clay model are presented in Table 2. In general, the differences between the S-wave velocities inside and outside of the clay volumes are approximately within one standard deviation of the calculated error of the models. Therefore, the differences of the S-wave velocities inside
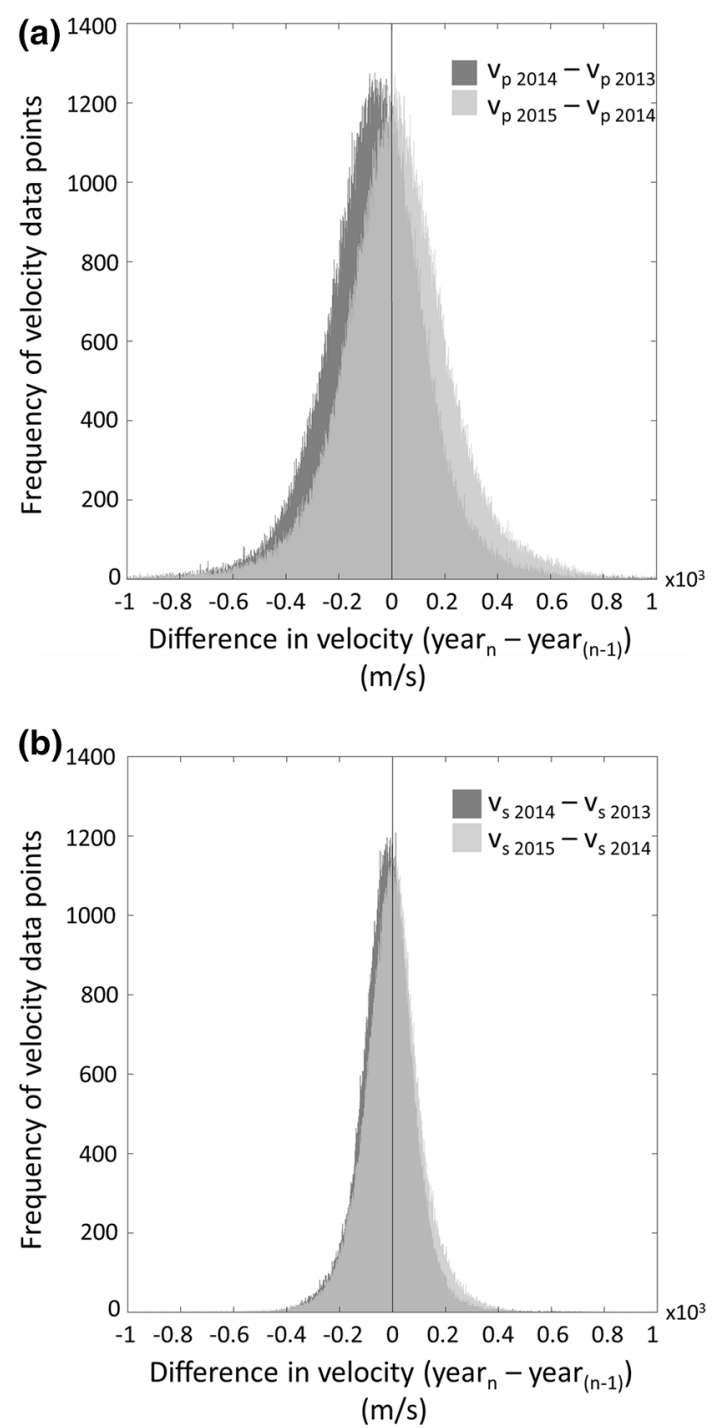

Fig. 1 Histograms of the differences in a P-wave velocity and $\mathbf{b}$ $\mathrm{S}$-wave velocity between the time periods. The dark distributions represent the difference between the 2014 and 2013 models, and the light distributions represent the difference between the 2015 and 2014 models and outside of the clay are not statistically significant. The $\mathrm{P}$-wave velocity shows a difference between inside and outside of the clay closer to two standard deviations. P-wave velocity from these tomographic models may thus be an indicator of clay volumes.

\section{Discussion}

The P-wave velocities showed possible correlation with extremely weak/soft geomechanical units. There is a very large stiffness differential between the clay volumes and the surrounding rock mass. It remains unclear if tomography can be used to identify the boundaries of geomechanical units with smaller stiffness differentials.

Other evaluated geomechanical characteristics were not identified using these tomographic models. It is important to note that these results are strongly dependent upon the used data sets. These results are only valid at Kiirunavaara Mine with the specific data sets, and the use of tomographic data to identify geomechanical characteristics has not been disproven. The specific tomographic and geomechanical models used in this analysis have some potential limitations that may influence the results, including:

- The passive tomography had a maximum resolution of $60 \mathrm{~m}$. Identification of any features smaller than this scale was not possible. Active source tomography may result in increased resolution, at a scale corresponding to identifiable geomechanical and/or mining features.

- The RQD model had a resolution of $60 \mathrm{~m}$, but it worth considering if geostatistical treatment of such data is of much geomechanical use. Although variograms showed that RQD data were correlated in space, RQD is designed for evaluation at the core scale to be used for design in the drift scale. The upscaling of RQD data associated with such geostatistical techniques may not be suitable to represent the large-scale changes in the rock mass identified by the tomography models of the Kiirunavaara mine, although an upper limit to this upscaling has not been determined. Issues with upscaling of standard geomechanical characterization data, which are most often designed for use at the drift scale, may be why there was a lack of correlation between the tomography model and
Table 1 Statistical properties of the differences in velocities between the 2013, 2014, and 2015 tomographic models

\begin{tabular}{llllllll}
\hline & \multicolumn{2}{c}{ Differences in P-wave velocity $(\mathrm{m} / \mathrm{s})$} & & \multicolumn{3}{c}{ Differences in S-wave velocity $(\mathrm{m} / \mathrm{s})$} \\
\cline { 2 - 3 } \cline { 6 - 8 } & $\mu$ & $\sigma$ & $2 \sigma$ & & $\mu$ & $\sigma$ & $2 \sigma$ \\
\hline $2014-2013$ & -61.6 & 207 & 415 & -18.8 & 106 & 213 \\
$2015-2014$ & 12.1 & 229 & 458 & -3.5 & 118 & 237 \\
Average & -24.7 & 218 & 436 & -11.1 & 112 & 225 \\
\hline
\end{tabular}


Fig. 2 RQD versus 2014 P-wave velocity

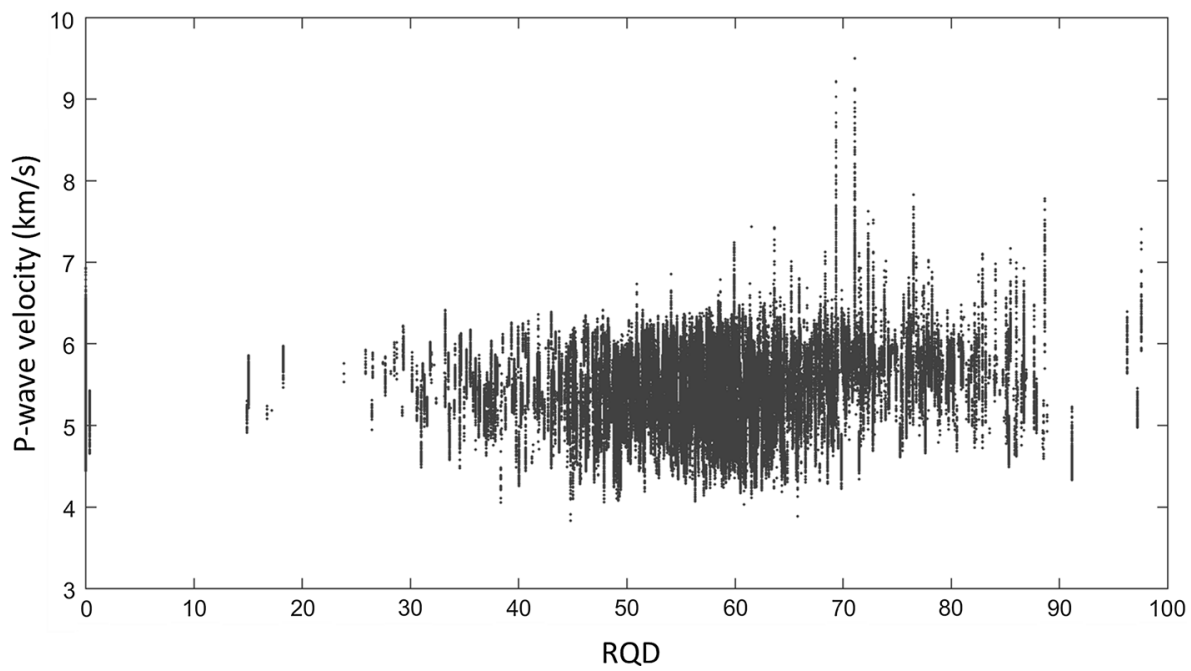

Table 2 Velocities inside and outside of clay volumes

\begin{tabular}{|c|c|c|c|c|c|}
\hline & $\begin{array}{l}\text { Tomography } \\
\text { model }\end{array}$ & $\begin{array}{l}\text { Inside clay, mean } \\
\text { velocity }(\mathrm{m} / \mathrm{s})\end{array}$ & $\begin{array}{l}\text { Outside clay, mean } \\
\text { velocity }(\mathrm{m} / \mathrm{s})\end{array}$ & $\begin{array}{l}\text { Difference in mean velocity, } \\
\text { outside-inside clay }(\mathrm{m} / \mathrm{s})\end{array}$ & $\begin{array}{l}\text { Difference in mean velocity/ } \\
\text { average standard deviation }\end{array}$ \\
\hline \multirow[t]{3}{*}{ P-wave velocity } & 2013 & 5520 & 5090 & -432 & 1.8 \\
\hline & 2014 & 5470 & 5100 & -375 & 1.6 \\
\hline & 2015 & 5510 & 5010 & -498 & 2.1 \\
\hline \multirow[t]{3}{*}{ S-wave velocity } & 2013 & 3110 & 3260 & 144 & 1.1 \\
\hline & 2014 & 3100 & 3280 & 180 & 1.4 \\
\hline & 2015 & 3100 & 3230 & 128 & 1.0 \\
\hline
\end{tabular}

the RQD model. This result may applicable to other large mines.

- S-wave velocities not showing a significant correlation with clay may be a natural result of the tomographic model. S-wave arrival times are often much more complicated and difficult to identify than P-wave arrival times. Therefore, the S-wave tomographic model is expected to have larger variation than the P-wave model, making it more challenging to identify geomechanical features.

As previously mentioned, this analysis evaluated precision of these tomographic models rather than accuracy. This worked well for comparative purposes, but to assess the other major benefit of tomographic models, event relocation using the 3-D velocity model from tomography, an analysis of accuracy is required.

Limited visibility of drifts in the tomographic model is expected due to the drifts having a smaller size than the resolution of the tomographic models. Stopes and caved material are notably larger than the drifts and may have a resolution compatible with tomography provided the coverage of the tomographic models is possible in those volumes. Although it was expected that the caved material would be identifiable by tomographic imaging, even where there was relatively good seismic network coverage near the production front, no differences in velocity were visually observed. Additional work on this is required.

\section{Concluding Remarks}

The possible correlation between the P-wave velocities and the clay model offers promise for the future use of tomographic data and models in mining environments, in addition to the obvious benefits of improved event locations. The lack of correlation between S-wave velocities and the clay model, and the tomographic models and the RQD model illustrates that in their current form, these tomographic models are not appropriate to be used alone to geomechanically characterize the rock mass. The need for additional and separate data sources to evaluate and interpret tomographic models is clear.

The analysis of the data derived from different scales has highlighted a potential limitation of conventional rock mass characterization techniques when applying them to very large scale, such as that of the Kiirunavaara Mine. It is clear that large-scale techniques to identify volumetric characteristics of rock masses are required in the field of rock 
mechanics. Passive tomography may be a technique that is capable of identifying these volumes within the large-scale rock mass that affect the stress field and resulting rock mass behaviour.

Acknowledgements This work would not have been possible without the assistance of Björn Lund, Karin Berglund, and Ari Tryggvason, who created the tomographic models. They are thanked for their collaboration, helpfulness, and endless patience. LKAB is thanked for their generous support of this project through many forms of resources including funding.

Open Access This article is distributed under the terms of the Creative Commons Attribution 4.0 International License (http://creativeco mmons.org/licenses/by/4.0/), which permits unrestricted use, distribution, and reproduction in any medium, provided you give appropriate credit to the original author(s) and the source, provide a link to the Creative Commons license, and indicate if changes were made.

\section{References}

Cai W, Dou L, Gong S, Li Z, Yuan S (2014) Quantitative analysis of seismic velocity tomography in rock burst hazard assessment. Nat Hazards 75:2453-2465. https://doi.org/10.1007/s1106 9-014-1443-6

Cao A, Dou L, Cai W, Gong S, Liu S, Jing G (2015) Case study of seismic hazard assessment in underground coal mining using passive tomography. Int J Rock Mech Min Sci 78:1-9. https://doi. org/10.1016/j.ijrmms.2015.05.001

Dahnér C, Malmgren L, Bošković M (2012) Transition from non-seismic mine to a seismically active mine: Kiirunavaara Mine. In: Rock Engineering and Technology for Sustainable Underground Construction. Presented at the The 2012 ISRM European Rock Mechanics Symposium (Eurock 2012), Stockholm, Sweden

Friedel MJ, Jackson MJ, Scott DF, Williams TJ, Olson MS (1995) 3-D tomographic imaging of anomalous conditions in a deep silver mine. J Appl Geophys 34:1-21. https://doi.org/10.1016/09269851(95)00007-O

Friedel MJ, Scott DF, Williams TJ (1997) Temporal imaging of mineinduced stress change using seismic tomography. Eng Geol 46:131-141. https://doi.org/10.1016/S0013-7952(96)00107-X

He H, Dou L, Li X, Qiao Q, Chen T, Gong S (2011) Active velocity tomography for assessing rock burst hazards in a kilometer deep mine. Min Sci Technol China 21:673-676. https://doi. org/10.1016/j.mstc.2011.10.003
Hemmati Nourani M, Taheri Moghadder M, Safari M (2017) Classification and assessment of rock mass parameters in Choghart iron mine using P-wave velocity. J Rock Mech Geotech Eng 9:318328. https://doi.org/10.1016/j.jrmge.2016.11.006

Hosseini N, Oraee K, Shahriar K, Goshtasbi K (2013) Studying the stress redistribution around the longwall mining panel using passive seismic velocity tomography and geostatistical estimation. Arab J Geosci 6:1407-1416. https://doi.org/10.1007/s1251 7-011-0443-z

Krauß F, Giese R, Alexandrakis C, Buske S (2014) Seismic travel-time and attenuation tomography to characterize the excavation damaged zone and the surrounding rock mass of a newly excavated ramp and chamber. Int J Rock Mech Min Sci 70:524-532. https:// doi.org/10.1016/j.ijrmms.2014.06.010

Lund B, Berglund K, Tryggvason A, Dineva S, Jonsson L (2017) Local event tomography in the Kiirunavaara iron ore mine, Sweden

Luxbacher K, Westman E, Swanson P, Karfakis M (2008) Threedimensional time-lapse velocity tomography of an underground longwall panel. Int J Rock Mech Min Sci 45:478-485. https://doi. org/10.1016/j.ijrmms.2007.07.015

Ma X, Westman EC, Fahrman BP, Thibodeau D (2016) Imaging of temporal stress redistribution due to triggered seismicity at a deep nickel mine. Geomech Energy Environ 5:55-64. https://doi. org/10.1016/j.gete.2016.01.001

Rawlinson N, Pozgay S, Fishwick S (2010) Seismic tomography: a window into deep Earth. Phys Earth Planet Inter 178:101-135. https://doi.org/10.1016/j.pepi.2009.10.002

Vatcher J, McKinnon SD, Sjöberg J (2014). Mine-scale numerical modelling, seismicity and stresses at Kiirunavaara Mine, Sweden. In: Hudyma MR, Potvin Y (eds) Proceedings of the seventh international seminar on deep and high stress mining. Presented at the deep mining 2014, ACG, Sudbury, Canada, pp 363-376

Vatcher J, McKinnon SD, Sjöberg J (2016) Developing 3-D mine-scale geomechanical models in complex geological environments, as applied to the Kiirunavaara Mine. Eng Geol 203:140-150. https ://doi.org/10.1016/j.enggeo.2015.07.020

Vatcher J, McKinnon SD, Sjöberg J (2017). A methodology to evaluate if geomechanical features are relevant to seismic behaviour. Submitted to an Int J

Watanabe T, Sassa K (1996) Seismic attenuation tomography and its application to rock mass evaluation. Int J Rock Mech Min Sci Geomech Abstr 33:467-477. https://doi.org/10.1016/01489062(96)00005-8

Young RP, Maxwell SC (1992) Seismic characterization of a highly stressed rock mass using tomographic imaging and induced seismicity. J Geophys Res Solid Earth 97:12361-12373. https://doi. org/10.1029/92JB00678 